\title{
Leucine acutely potentiates glucose-stimulated insulin secretion in fetal sheep
}

\author{
Brit H Boehmer, Peter R Baker II, Laura D Brown, Stephanie R Wesolowski and Paul J Rozance \\ Department of Pediatrics, University of Colorado School of Medicine, Perinatal Research Center, Aurora, Colorado, USA
}

Correspondence should be addressed to P J Rozance: Paul.Rozance@ucdenver.edu

\begin{abstract}
A 9-day infusion of leucine into fetal sheep potentiates fetal glucose-stimulated insulin secretion (GSIS). However, there were accompanying pancreatic structural changes that included a larger proportion of $\beta$-cells and increased vascularity. Whether leucine can acutely potentiate fetal GSIS in vivo before these structural changes develop is unknown. The mechanisms by which leucine acutely potentiates GSIS in adult islets and insulinsecreting cell lines are well known. These mechanisms involve leucine metabolism, including leucine oxidation. However, it is not clear if leucine-stimulated metabolic pathways are active in fetal islets. We hypothesized that leucine would acutely potentiate GSIS in fetal sheep and that isolated fetal islets are capable of oxidizing leucine. We also hypothesized that leucine would stimulate other metabolic pathways associated with insulin secretion. In pregnant sheep we tested in vivo GSIS with and without an acute leucine infusion. In isolated fetal sheep islets, we measured leucine oxidation with a $\left[1-{ }^{14} \mathrm{C}\right]$ L-leucine tracer. We also measured concentrations of other amino acids, glucose, and analytes associated with cellular metabolism following incubation of fetal islets with leucine. In vivo, a leucine infusion resulted in glucose-stimulated insulin concentrations that were over $50 \%$ higher than controls $(P<0.05)$. Isolated fetal islets oxidized leucine. Leucine supplementation of isolated fetal islets also resulted in significant activation of metabolic pathways involving leucine and other amino acids. In summary, acute leucine supplementation potentiates fetal GSIS in vivo, likely through pathways related to the oxidation of leucine and catabolism of other amino acids.
\end{abstract}

Key Words
- leucine
- insulin
- pancreas
- islet
- $\beta$-cell
- fetus
- sheep

\section{Introduction}

Metabolism of nutrients by the $\beta$-cell in the pancreatic islet is key to nutrient-stimulated insulin secretion. This is described by the fuel-mediated hypothesis of insulin release (Malaisse et al. 1979). The fuel-mediated hypothesis posits that nutrient-stimulated insulin release depends on the capacity of nutrients to be metabolized by the $\beta$-cell as an energy source. In the adult islet, leucine increases its own oxidative metabolism. Leucine also stimulates glucose metabolism by allosterically activating glutamate dehydrogenase $(\mathrm{GDH})$. GDH converts glutamate to $\alpha$-ketoglutarate, thereby increasing the activity of the tricarboxylic acid pathway (Fajans et al. 1967, Malaisse et al. 1980, Sener \& Malaisse 1980, McClenaghan et al. 1996, Gao et al. 2003, Li et al. 2003). Therefore, consistent with the fuel-mediated hypothesis of insulin secretion leucine stimulates insulin release from adult islets by increasing cellular energy production (Malaisse et al. 1979).

Among the various amino acids that can impact $\beta$-cell metabolism and function, leucine is particularly relevant to study in the fetal period as it has the potential for 
stimulating pancreatic islet growth, development, and insulin secretion (Rozance \& Hay Jr 2016, Boehmer et al. 2017). We have demonstrated that leucine potentiates GSIS in vitro in isolated fetal sheep islets (Rozance et al. 2006, Benjamin et al. 2017). We also have demonstrated that a 9-day infusion of leucine into fetal sheep at a rate adjusted to double fetal arterial plasma leucine concentrations potentiated fetal GSIS without increasing non-glucose-stimulated fetal insulin concentrations (Boehmer et al. 2020). After the 9-day infusion of leucine, insulin $^{+} \beta$-cells comprised a larger proportion of the pancreas and pancreatic islet. There also was higher pancreatic and pancreatic islet vascularity (Boehmer et al. 2020). Therefore, it was not clear whether potentiation of GSIS by leucine was due to these structural changes or if leucine can acutely potentiate fetal GSIS in vivo. Furthermore, whether the same leucine stimulated metabolic signaling pathways observed in adult islets are active in fetal islets is unknown. Therefore, we used fetal sheep to demonstrate that leucine acutely potentiates fetal GSIS in vivo. We also used isolated fetal sheep islets to test the hypothesis that these islets have the capacity to oxidize leucine and that leucine increases the products of cellular metabolism in vitro.

\section{Materials and methods}

\section{In vivo leucine potentiated GSIS}

All animal experiments were conducted at the Perinatal Research Center, University of Colorado School of Medicine, Aurora, Colorado, in compliance with ARRIVE guidelines. The Institutional Animal Care and Use Committee approved this study. The Perinatal Research Center Center is accredited by the Association for Assessment and Accreditation of Laboratory Animal Care. In vivo leucine potentiated GSIS studies were conducted in five Columbia-Rambouillet sheep with singleton pregnancies. Animals were anesthetized at $121 \pm 1$ days of gestational age (dGA) and surgeries performed to place indwelling catheters into the fetal abdominal aorta, fetal femoral vein, and maternal femoral vein and artery as previously described (Rozance et al. 2006). Before insulin secretion was measured, animals were allowed to recover for at least 5 days.

GSIS was measured with a 90-min variable rate, square-wave, fetal hyperglycemic clamp initiated at time 0 min (Gadhia et al. 2013). At -105 and -100 min, fetal blood was sampled for baseline hormone, nutrient and blood gas concentrations. At $-90 \mathrm{~min}$ an experimental infusion into a fetal vein was started. The infusion was either leucine (752 $\mu \mathrm{mol} / \mathrm{h}$; Sigma-Aldrich) or saline $(0.3 \mathrm{~mL} / \mathrm{h}$ to match the sodium delivery in the leucine infusion). Fetal blood was then sampled at -15 and $-10 \mathrm{~min}$ to measure the response to the experimental leucine infusion and to determine insulin and glucose concentrations prior to the hyperglycemic clamp. The hyperglycemic clamp was then started and fetal blood samples were taken at minutes 5, 10, 15, 20, 30, 45, 60, 75, and 90 to measure insulin and glucose concentrations. The total blood volume removed for each study was between 13 and $15 \mathrm{~mL}$. Experimental infusions were continued for the duration of the hyperglycemic clamp. Animals had GSIS measured multiple times, always with at least $48 \mathrm{~h}$ between measurements. The experimental infusion (leucine or saline) was alternated and fetuses had leucinepotentiated GSIS measured twice and GSIS following the saline infusion measured one to three times. The rationale for measuring GSIS multiple times during the leucine and saline infusions is that we did not have preliminary data indicating the effect size of leucine on the potentiation of GSIS. We also did not have an estimate of the within animal variability for leucine potentiated GSIS. Therefore, we prospectively measured leucine potentiated GSIS and GSIS without a leucine infusion multiple times in each animal. Results from this study were analyzed in a mixed models ANOVA in SAS v. 9.2 with terms to account for repeated measures within the same fetus and within the same study. Time, experimental infusion (leucine or saline), and their interaction were included as fixed terms. Individual means were compared with Fisher's least squares difference test. $P$-values $\leq 0.05$ were accepted as significant. For Fig. 1 and Table 1 the concentrations for an animal during either the leucine or saline infusion studies were averaged, and these means were used to calculate group means and variances for leucine and saline potentiated GSIS. Blood was sampled from arterial catheters except for one animal's studies. For this fetus blood could only be sampled from a venous catheter and so these biochemical values are only included in the glucose and insulin concentration analyses during the GSIS studies (Fig. 1). No data points were excluded as outliers.

\section{Biochemical analyses}

Biochemical analysis was performed as previously described (Culpepper et al. 2016). Blood was analyzed immediately after collection for $\mathrm{pH}, \mathrm{O}_{2}, \mathrm{CO}_{2}$, and hemoglobin (ABL825; Radiometer America Inc., 


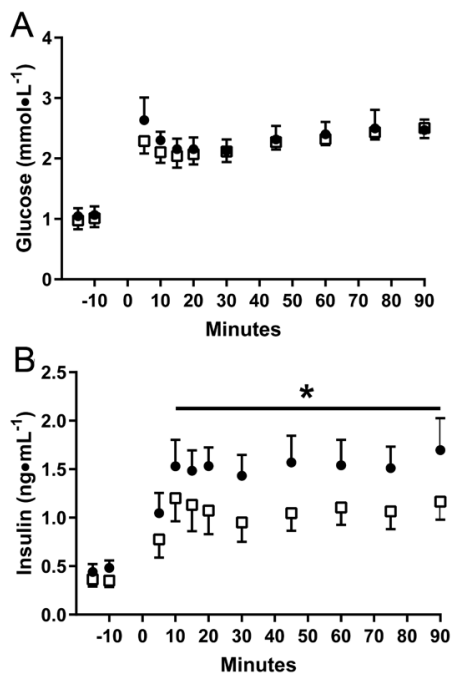

Figure 1

In vivo fetal GSIS is potentiated by leucine. Mean \pm S.E.M. fetal arterial plasma glucose (A) and insulin (B) concentrations are shown relative to the start of a primed continuous variable rate fetal hyperglycemic clamp (time $=0 \mathrm{~min}$ ). At time -90 an experimental infusion of leucine (752 $\mu \mathrm{mol} / \mathrm{h}$, closed circles) or saline $(0.3 \mathrm{~mL} / \mathrm{h}$, open squares) was started. Means are calculated from experiments conducted in five animals in which the experimental infusion was alternated. Animals had GSIS measured multiple times, always with at least $48 \mathrm{~h}$ between measurements. All fetuses had leucine potentiated GSIS measured twice and GSIS following the saline infusion measured one to three times. The concentrations for a single animal during either the leucine or saline infusion studies were averaged, and these means were used to calculate group means and variances in the figure. Results were analyzed in a mixed models ANOVA and individual means were compared with Fisher's least squares difference test. * Significantly higher glucose-stimulated insulin concentrations during the leucine infusion compared to the saline infusion ( $P \leq 0.05$; with the exception of minute $15, P=0.056$ ).

Brea, CA, USA), as well as plasma concentrations of glucose and lactate (YSI 2700 biochemistry analyzer; Yellow Springs Instruments, Yellow Springs, OH, USA). Additional plasma was stored at $-80^{\circ} \mathrm{C}$ for measurement of insulin (intra- and inter-assay CVs 5.6 and $4.7 \%$, respectively), insulin-like growth factor-1 (IGF-I; intra- and inter-assay CVs 3.1 and 5.6\%, respectively), and cortisol (intra- and inter-assay CVs 5.6 and $4.7 \%$, respectively) by ELISA (ALPCO Immunoassays, Salem, NH, USA); glucagon by RIA (intra- and inter-assay CVs 4.8 and $11.7 \%$, respectively; Millipore) and norepinephrine by HPLC (intra- and interassay CVs 9.2 and 9.0\%, respectively).

\section{Pancreatic islet isolation}

Pancreatic islets were isolated from four of the five animals subjected to measurement of in vivo leucine-potentiated GSIS at least 1 day after the last in vivo study. These islets were used to determine the impact of supplemental leucine on a wide range of pancreatic analytes.
We also isolated pancreatic islets from four additional late gestation fetal sheep. These islets were used to measure leucine oxidation. All four of these fetuses underwent a surgery to place maternal and fetal catheters. Two of these fetuses had an acute hyperinsulinemic-euglycemic clamp performed and two had baseline physiologic studies performed without acute clamp studies prior to collection of pancreatic islets. Their gestational age at the time of pancreatic islet collection was $131 \pm 2$. All islets were isolated by collagenase digestion, as previously described (Rozance et al. 2006). The animals were anesthetized with ketamine (10-25 mg/kg) and diazepam (0.1-0.3 mg/kg) administered intravenously to the ewe. After the umbilical cord was clamped and divided, the ewe was euthanized with an overdose of Fatal Plus pentobarbital solution. The fetus also was euthanized with an overdose of Fatal Plus given intravenous or intracardiac.

\section{Pancreatic islet leucine oxidation}

Fetal sheep pancreatic islet leucine oxidation rates were determined as previously described for glucose oxidation with the exception that we used $\left[1-{ }^{14} \mathrm{C}\right]$ L-leucine instead of [U-14C] D-glucose (Rozance et al. 2007). Briefly, fetal sheep islet leucine oxidation rates were determined for four different fetuses. Islets were placed in a $1 \mathrm{~mL}$ Nunc CryoTube (1 mL; Nalge Nunc International, Naperville, IL, USA) affixed with epoxy inside a $20 \mathrm{~mL}$ glass scintillation vial ( $n=3-5$ per incubation condition, 25 islets each) and sealed with a Suba-Seal Rubber Septa (Sigma-Aldrich). Islets were incubated in Krebs-Ringer bicarbonate buffer with $0.5 \%$ BSA (w/v) containing $1.1 \mathrm{mmol} / \mathrm{L}$ D-glucose and $0.4,4$, or $10 \mathrm{mmol} / \mathrm{L}$ L-leucine with $[1-14 \mathrm{C}]$ L-leucine $(8$, 12 or $16 \mu \mathrm{Ci} / \mathrm{mL}$, respectively (New England Nucleotides, Boston, MA, USA) for $2 \mathrm{~h}$. Prior to the addition of isolated islets, the buffer was pre-equilibrated in $95 \% \mathrm{O}_{2}: 5 \% \mathrm{CO}_{2}$. Blank reactions without islets were included. At the end of the $2 \mathrm{~h}$ incubation reaction vials were quickly cooled and the reaction stopped with $100 \mu \mathrm{L}$ of $1 \mathrm{~mol} / \mathrm{L} \mathrm{HCl}$. Solvable (0.5 mL, Perkin Elmer) was added to the base of the scintillation vial to trap the $\mathrm{CO}_{2}$ while the vials were incubated at $37^{\circ} \mathrm{C}$ with gentle agitation for $90 \mathrm{~min}$. The rubber stopper and reaction tube were removed, Ultima Gold scintillation fluid (Perkin Elmer) was added, and the captured ${ }^{14} \mathrm{CO}_{2}$ disintegrations per minute (DPM) were determined with a Packard Tri-Carb 2300TR Liquid Scintillation Analyzer. The rate of leucine oxidation (pmol/islet/h) was calculated by dividing the difference between the DPMs from the islet incubations and the blank incubations by the specific activity of leucine in 
Table 1 Fetal nutrient, hormone and blood gas measurements prior to in vivo hyperglycemic clamp study.

\begin{tabular}{|c|c|c|c|c|}
\hline & \multicolumn{2}{|c|}{ Saline } & \multicolumn{2}{|c|}{ Leucine } \\
\hline & Pre & Post-75 min & Pre & Post-75 mins \\
\hline \multicolumn{5}{|c|}{ Plasma substrates and hormones } \\
\hline Leucine ( $\mu \mathrm{mol} / \mathrm{L})$ & $153 \pm 25$ & $146 \pm 21$ & $133 \pm 3$ & $287 \pm 16^{b}$ \\
\hline Glucose (mmol/L) & $0.9 \pm 0.1$ & $1.0 \pm 0.1$ & $1.0 \pm 0.1$ & $1.1 \pm 0.1$ \\
\hline Insulin (ng/mL) & $0.35 \pm 0.08$ & $0.36 \pm 0.09$ & $0.36 \pm 0.07$ & $0.46 \pm 0.10^{b}$ \\
\hline Glucagon (pg/mL) & $80.4 \pm 18.7$ & $87.3 \pm 18.9$ & $59.8 \pm 11.4$ & $81.4 \pm 17.6$ \\
\hline IGF-1 (ng/mL) & $98.4 \pm 22.6$ & $94.4 \pm 20.3$ & $97.4 \pm 19.9$ & $101.1 \pm 19.9$ \\
\hline Norepinephrine (pg/mL) & $343.4 \pm 44.3$ & $338.2 \pm 40.4$ & $433.9 \pm 57.7$ & $380.3 \pm 59.8$ \\
\hline Cortisol (ng/mL) & $22.4 \pm 6.1$ & $22.0 \pm 6.5$ & $18.8 \pm 5.6$ & $16.9 \pm 5.6$ \\
\hline Lactate (mmol/L) & $1.77 \pm 0.08$ & $1.80 \pm 0.04$ & $1.91 \pm 0.24$ & $2.15 \pm 0.28^{a}$ \\
\hline Alanine $(\mu \mathrm{mol} / \mathrm{L})$ & $238.2 \pm 14.5$ & $230.4 \pm 14.7$ & $248.7 \pm 10.8$ & $238.0 \pm 12.9$ \\
\hline Arginine $(\mu \mathrm{mol} / \mathrm{L})$ & $93.3 \pm 11.2$ & $95.5 \pm 9.7$ & $84.2 \pm 11.5$ & $88.8 \pm 9.0$ \\
\hline Asparagine $(\mu \mathrm{mol} / \mathrm{L})$ & $38.9 \pm 3.7$ & $38.8 \pm 2.6$ & $37.2 \pm 3.9$ & $34.1 \pm 4.0$ \\
\hline Aspartate $(\mu \mathrm{mol} / \mathrm{L})$ & $17.3 \pm 2.2$ & $17.5 \pm 2.8$ & $19.9 \pm 2.5$ & $19.8 \pm 3.5$ \\
\hline Citruline $(\mu \mathrm{mo} / \mathrm{L})$ & $187.0 \pm 52.2$ & $184.9 \pm 48.7$ & $198.4 \pm 32.4$ & $186.7 \pm 43.4$ \\
\hline Cysteine ( $\mu \mathrm{mol} / \mathrm{L})$ & $11.3 \pm 1.8$ & $11.1 \pm 1.7$ & $13.3 \pm 3.1$ & $10.1 \pm 1.1$ \\
\hline Glutamate $(\mu \mathrm{mol} / \mathrm{L})$ & $27.9 \pm 7.3$ & $26.6 \pm 7.1$ & $33.1 \pm 7.3$ & $34.4 \pm 6.0$ \\
\hline Glutamine $(\mu \mathrm{mol} / \mathrm{L})$ & $324.2 \pm 10.9$ & $311.8 \pm 8.4$ & $331.8 \pm 15.9$ & $339.2 \pm 15.8$ \\
\hline Glycine ( $\mu \mathrm{mol} / \mathrm{L})$ & $347.0 \pm 58.1$ & $331.8 \pm 51.0$ & $334.0 \pm 41.1$ & $302.9 \pm 36.2$ \\
\hline Histidine $(\mu \mathrm{mol} / \mathrm{L})$ & $52.7 \pm 1.6$ & $50.4 \pm 4.5$ & $50.8 \pm 5.0$ & $46.7 \pm 1.9$ \\
\hline Isoleucine $(\mu \mathrm{mol} / \mathrm{L})$ & $128.4 \pm 10.0$ & $127.0 \pm 10.4$ & $110.7 \pm 5.1$ & $106.2 \pm 4.5$ \\
\hline Lysine $(\mu \mathrm{mol} / \mathrm{L})$ & $82.8 \pm 7.0$ & $78.6 \pm 4.3$ & $79.4 \pm 10.7$ & $77.5 \pm 11.0$ \\
\hline Methionine ( $\mu \mathrm{mol} / \mathrm{L})$ & $96.2 \pm 10.3$ & $90.3 \pm 11.9$ & $89.9 \pm 3.7$ & $84.4 \pm 4.6$ \\
\hline Ornithine $(\mu \mathrm{mol} / \mathrm{L})$ & $74.3 \pm 11.4$ & $73.6 \pm 10.7$ & $71.2 \pm 8.4$ & $76.3 \pm 10.5$ \\
\hline Phenylalanine $(\mu \mathrm{mol} / \mathrm{L})$ & $95.0 \pm 9.1$ & $92.7 \pm 9.0$ & $89.7 \pm 8.3$ & $88.5 \pm 10.1$ \\
\hline Proline $(\mu \mathrm{mol} / \mathrm{L})$ & $135.4 \pm 6.6$ & $127.4 \pm 4.8$ & $125.3 \pm 9.8$ & $116.3 \pm 7.9$ \\
\hline Serine $(\mu \mathrm{mol} / \mathrm{L})$ & $382.6 \pm 27.2$ & $365.2 \pm 26.2$ & $402.8 \pm 35.2$ & $385.5 \pm 36.5$ \\
\hline Taurine $(\mu \mathrm{mol} / \mathrm{L})$ & $41.6 \pm 6.1$ & $40.8 \pm 9.3$ & $42.8 \pm 7.6$ & $38.9 \pm 7.4$ \\
\hline Threonine $(\mu \mathrm{mol} / \mathrm{L})$ & $217.3 \pm 54.7$ & $204.3 \pm 53.6$ & $221.4 \pm 52.0$ & $202.7 \pm 47.7$ \\
\hline Tryptophan $(\mu \mathrm{mol} / \mathrm{L})$ & $40.0 \pm 4.2$ & $36.6 \pm 2.8$ & $43.4 \pm 3.6$ & $35.8 \pm 3.0$ \\
\hline Tyrosine ( $\mu \mathrm{mol} / \mathrm{L})$ & $131.2 \pm 10.2$ & $126.8 \pm 14.0$ & $121.6 \pm 13.4$ & $112.7 \pm 12.0$ \\
\hline Valine $(\mu \mathrm{mol} / \mathrm{L})$ & $428.8 \pm 30.2$ & $411.5 \pm 27.3$ & $388.8 \pm 13.4$ & $361.8 \pm 12.1$ \\
\hline \multicolumn{5}{|l|}{ Blood gas measurements } \\
\hline $\mathrm{pH}$ & $7.35 \pm 0.00$ & $7.35 \pm 0.00$ & $7.35 \pm 0.00$ & $7.34 \pm 0.00$ \\
\hline $\mathrm{PaCO}_{2}(\mathrm{mmHg})$ & $49.6 \pm 1.2$ & $49.1 \pm 1.4$ & $50.5 \pm 0.5$ & $50.6 \pm 0.8$ \\
\hline $\mathrm{PaO}_{2}(\mathrm{mmHg})$ & $19.6 \pm 0.7$ & $19.1 \pm 1.2$ & $20.1 \pm 0.8$ & $19.6 \pm 1.2$ \\
\hline Hemoglobin (g/dL) & $6.48 \pm 0.32$ & $6.47 \pm 0.32$ & $6.55 \pm 0.31$ & $6.49 \pm 0.29$ \\
\hline $\mathrm{SaO}_{2}(\%)$ & $47.8 \pm 2.5$ & $46.1 \pm 4.2$ & $48.7 \pm 3.2$ & $46.6 \pm 4.7$ \\
\hline $\mathrm{O}_{2}$ content $(\mathrm{mmol} / \mathrm{L})$ & $3.01 \pm 0.07$ & $2.91 \pm 0.15$ & $3.12 \pm 0.19$ & $2.98 \pm 0.32$ \\
\hline
\end{tabular}

Values are the mean \pm S.E.M. $P$ values are from a mixed models ANOVA with individual means comparisons leucine infusion with both the pre-leucine infusion and post-75 min saline infusion concentrations. $\mathrm{b} P<0.0001$ for the comparison between post-75 min leucine infusion and pre-leucine infusion concentrations, and $P<0.05$ for the comparison between post-75 min leucine infusion with the post-75 min saline infusion concentrations. ${ }^{P}<0.0001$ for the comparison between 75 min post-leucine infusion with pre-leucine infusion concentrations. $n=4$ animals that were studied for each infusion type.

the buffer. Oxidation rates were log transformed before being analyzed with repeated measures ANOVA in SAS v. 9.2. Individual means were compared with Fisher's least squares difference test. $P$-values $\leq 0.05$ were accepted as significant. Incubation in $4 \mathrm{mmol} / \mathrm{L}$ L-leucine was not performed for one of the sets of islets. No data points were excluded as outliers.

\section{Pancreatic islet analyte measurement}

Pancreatic islets were isolated from four fetal sheep and separated into equal batches of at least 250 islets, as previously described (Rozance et al. 2006). Islets were incubated for $24 \mathrm{~h}$ in RPMI 1640 (Sigma-Aldrich) supplemented with glucose $(2.8 \mathrm{mmol} / \mathrm{L})$, BSA $(0.5 \%$, $\mathrm{w} / \mathrm{v})$, and \pm leucine $(10 \mathrm{mmol} / \mathrm{L})$ at $37^{\circ} \mathrm{C}$ in $95 \% \mathrm{O}_{2}-5 \%$ $\mathrm{CO}_{2}$. Following this, islets and conditioned media were separated by centrifugation. The islets were resuspended in PBS and separated into individual cells with a 3-min trypsin digest. PBS was added to the cell suspension such that a final concentration of $2 \times 10^{6}$ cells $/ \mathrm{mL}$ was achieved. RPMI 1640 with supplements noted above was added to the conditioned media samples to normalize for numbers of cells that were present in the 
overnight incubations. Samples were submitted to the Biological Mass Spectrometry Facility (University of Colorado School of Medicine) for measurement of 140 hydrophilic analytes, as previously described (Nemkov et al. 2015, 2017). Analytes were extracted from cell pellets in ice-cold methanol:acetonitrile:water $(5: 3: 2, \mathrm{v} / \mathrm{v} / \mathrm{v})$ at a ratio of $2 \times 10^{6}$ cells $/ \mathrm{mL}$. Islet lysates and conditioned media were agitated for $30 \mathrm{~min}$ and vortexed for $10 \mathrm{~min}$ at $4^{\circ} \mathrm{C}$. Samples were then centrifuged for $10 \mathrm{~min}$ at $10,000 \boldsymbol{g}$ and $4^{\circ} \mathrm{C}$, supernatants were removed and stored at $-80^{\circ} \mathrm{C}$. Cell extracts and conditioned media (20 and $5 \mu \mathrm{L}$, respectively) were injected into Vanquish Ultra High Performance Liquid Chromatography (UHPLC) system coupled online to a Q Exactive mass spectrometer (Thermo Fisher Scientific) and separated through a 3-min isocratic elution on a Kinetex C18 column $(150 \times 2.1 \mathrm{~mm}$ i.d., $1.7 \mu \mathrm{m}$ particle size; Phenomenex, Torrance, CA, USA) at $250 \mu \mathrm{L} / \mathrm{min}$ (mobile phase: 5\% acetonitrile, $95 \%$ water and $0.1 \%$ formic acid; column temperature: $25^{\circ} \mathrm{C}$ ). The Q Exactive mass spectrometer was operated in both positive and negative ion mode. Scanning was performed in Full MS mode ( 2 uscans) from 60 to $900 \mathrm{~m} / \mathrm{z}$ at 70,000 resolution with $4 \mathrm{kV}$ spray voltage, 15 sheath gas, and 5 auxiliary gas. Calibration was performed prior to analysis using PierceTM Positive and Negative Ion Calibration Solutions (Thermo Fisher Scientific). Data for leucine and isoleucine obtained via UHPLC were combined due to co-elution of peak areas. Additionally, because UHPLC measurements of amino acids are not as accurate as amino acid concentrations measured by high performance liquid chromatography (HPLC), we also used HPLC to measure concentrations in separate aliquots of conditioned media as previously described (Brown et al. 2012). Leucine and isoleucine were quantified separately via HPLC. Glucose concentrations in the media were measured with the YSI 2700 biochemistry analyzer. For reference, glucose and amino acid concentrations were also measured in media that was not used to incubate islets. No data points were excluded as outliers.

Comparison of analytes in islets and media was performed by Paired T-test. This was done in GraphPad Prism V8.2 for HPLC and YSI measurements and in MetaboAnalyst for UHPLC measurements. For the UHPLC measurements, false discovery rate (FDR) was determined using Benjamini-Hochberg procedure (Hochberg \& Benjamini 1990). Analyte annotation was performed using the KEGG database. Pathway analyses was performed using Metaboanalyst using the KEGG database for annotation with enrichment of relevant pathways determined by the global test method and topological analysis determined using relative betweenness centrality. Analytes with a nominal $P$ value $\leq 0.05$ and an FDR $<0.25$ were used for pathway analysis. Statistical significance for glucose concentrations and amino acid concentrations measured by HPLC and for pathway analysis was set at $P \leq 0.05$. Media glycine, leucine, and serine concentrations determined by HPLC were log transformed for statistical analysis. No data points were excluded as outliers.

\section{Results}

\section{Fetal leucine potentiated GSIS}

Fetal sheep were subjected to a square-wave hyperglycemic clamp with or without a direct fetal leucine infusion. Averaged fetal arterial blood gases and plasma nutrient and hormone concentrations from the -105 and -100 min blood draws and the -15 and -10 min blood draws are shown in Table 1 . As each fetus was subjected to multiple tests of GSIS, we analyzed minute -105 and -100 fetal hemoglobin concentrations as a function of the order of the GSIS test and found that between the first and second time GSIS was measured there was a consistent $7 \%$ reduction in fetal hemoglobin $(P<0.05)$. There was no further reduction in fetal hemoglobin after the second GSIS test. This small reduction in fetal hemoglobin did not impact GSIS. The leucine infusion resulted in plasma leucine concentrations that were almost twice as high as in the saline infused fetuses $(P<0.0001)$. No other amino acid concentrations were impacted by the leucine infusion. Glucose concentrations also were not impacted by the leucine infusion, though lactate concentrations increased $12.5 \%$ with the leucine infusion $(P<0.0001)$ but not with the saline infusion. Plasma insulin concentrations increased with the leucine infusion $(P<0.0001)$ and were about $25 \%$ higher compared to insulin concentrations with the saline infusion $(P<0.05)$.

During the hyperglycemic clamp, insulin concentrations were greater with the concurrent leucine infusion starting at minute 10 of the hyperglycemic clamp $(P<0.05$; Fig. 1) compared to insulin concentrations with the saline infusion. Glucose concentrations were similar for the duration of the hyperglycemic clamp with the exception of minute 5 , when they were $5 \%$ greater during the leucine infusion compared to the saline infusion $(P<0.05)$. https://joe.bioscientifica.com

https://doi.org/10.1530/JOE-20-0243 (c) 2020 Society for Endocrinology Published by Bioscientifica Ltd.
Printed in Great Britain 


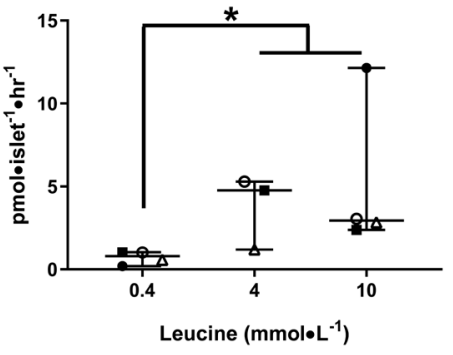

Figure 2

Isolated fetal pancreatic islets oxidize leucine. Pancreatic islets were isolated from four late gestation fetal sheep and incubated with 1.1 $\mathrm{mmol} / \mathrm{L}$ glucose and increasing concentrations of leucine. Data points with the same symbol were derived from a single animal's islets. Median and $95 \%$ confidence intervals are shown. Leucine oxidation was measured by including $\left[1-{ }^{14} \mathrm{C}\right]$ L-leucine in the incubation buffer and measuring $\left[{ }^{14} \mathrm{C}\right] \mathrm{CO}_{2}$ production. Incubations in 0.4 and $10 \mathrm{mmol} / \mathrm{L}$ leucine include islets from all four fetuses and incubations in $4 \mathrm{mmol} / \mathrm{L}$ include islets from three of the four fetuses. For statistical analysis, results were log transformed and then analyzed with a repeated measures ANOVA. Individual means of the log transformed data were compared with Fisher's least squares difference test. *Significantly greater leucine oxidation rate with incubations in 4 and $10 \mathrm{mmol} / \mathrm{L}$ leucine compared to $0.4 \mathrm{mmol} / \mathrm{L}(P<0.05)$

\section{Pancreatic islet leucine oxidation}

In order to demonstrate that isolated fetal pancreatic islets have the capacity to oxidize leucine, islets were incubated with various concentrations of $\left[1-{ }^{14} \mathrm{C}\right]$ L-leucine and the production of $\left[{ }^{14} \mathrm{C}\right] \mathrm{CO}_{2}$ was measured (Fig. 2). Islet leucine oxidation rates were greater with incubations in 4 and $10 \mathrm{mmol} / \mathrm{L}$ leucine compared to $0.4 \mathrm{mmol} / \mathrm{L}$ leucine $(P<0.05)$. There was no statistical difference between the oxidation rates with incubations in 4 and $10 \mathrm{mmol} / \mathrm{L}$ leucine, perhaps indicating a maximal oxidative capacity for leucine.

\section{Analytes following islet incubation with supplemental leucine}

HPLC analysis demonstrated the targeted 25-fold higher leucine concentrations in media from islets treated with supplemental leucine (9498 \pm 92 leucine supplemented vs $367 \pm 2$ non-supplemented nmol/mL, $P<0.0001)$. The media concentrations of glucose and almost all other amino acids were between 5-30\% lower in media from leucine supplemented islets compared to non-leucine supplemented islets $(P<0.05 ;$ Fig. 3$)$. Proline was not different between experimental conditions. Isoleucine was $15 \%$ higher in leucine supplemented media compared to non-supplemented media $(P<0.0001$, Fig. 3). Insulin concentrations in the media did not consistently differ between treatments (158 \pm 90 leucine supplemented vs $118 \pm 50$ non-supplemented $\mathrm{ng} / \mathrm{mL}$ ).

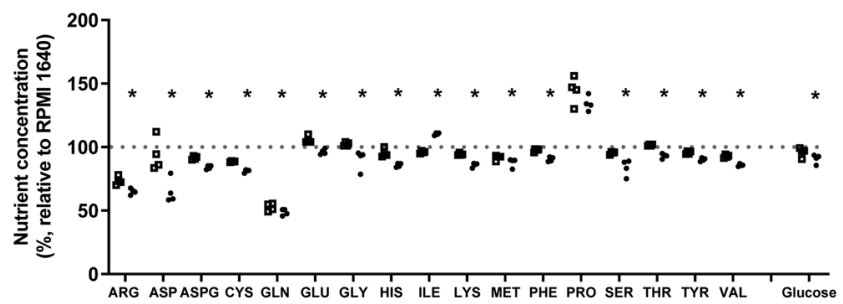

\section{Figure 3}

Supplemental leucine results in lower concentrations of other amino acids after incubation with isolated fetal islets. Fetal islets from four sheep were divided into equal aliquots and incubated in control media (open squares) or control media supplemented with leucine $(10 \mathrm{mmol} / \mathrm{L}$, closed circles). Media was then subjected to measurement of amino acids or glucose and results were normalized to the concentrations of these nutrients in reference media that was not exposed to isolated islets. Data are mean \pm S.E.M. *Significant difference between media from islets that were supplemented with leucine vs media from islets that were not supplemented with leucine $(P<0.05)$ by paired $t$-test. ARG, arginine; ASP, aspartate; ASPG, asparagine; CYS, cysteine; GLN, glutamine; GLU, glutamate; GLY, glycine; HIS, histidine; ILE, isoleucine; LYS, lysine; MET, methionine; PHE, phenylalanine; PRO, proline; SER, serine; THR, threonine; TYR, tyrosine; VAL, valine.

UHPLC/mass spectrometry analysis measured 140 analytes in the islets and 120 analytes in the media (Table 2 and Supplementary Table 1, see section on supplementary materials given at the end of this article). Principal component analyses (PCA) confirmed a segregation of analytes from leucine supplemented and non-supplemented islets (Fig. 4A). This segregation was more distinct in the conditioned media (Fig. 4B). Of the analytes measured in islets and media, KEGG database annotations were available for 130 and 107, respectively, and thus these analytes were used for pathway analyses if they were significantly different between groups (nominal $P$ Value $\leq 0.05)$. For analytes obtained from the islets, nine achieved statistical significance ( $P \leq 0.05$; Table 2$)$. Notable islet analytes with significant differences included L-leucine (seven-fold higher, $P<0.05$ ) and its related catabolite propionyl-carnitine being $80 \%$ lower $(P<0.05)$ in leucine supplemented islets (Table 2), thus confirming that leucine entered the islet cells and underwent cellular catabolism. However, no pathways demonstrated significant enhancement using analytes from the islets with a nominal $P$ value of $\leq 0.05$ and an FDR $<0.25$.

For analytes obtained from the media, 39 achieved statistical significance ( $P \leq 0.05$; Table 2$)$. Seven pathways demonstrated significant enrichment using analytes from the conditioned media with a nominal $P$ Value $\leq 0.05$ and an FDR $<0.25$ (Table 3). Consistent with the lower media concentrations of almost all amino acids as measured by HPLC, the pathway analysis indicated significant involvement of metabolic processes involving all 


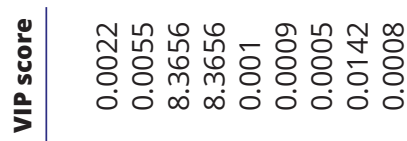

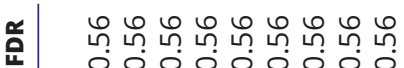

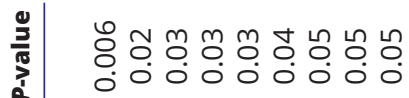

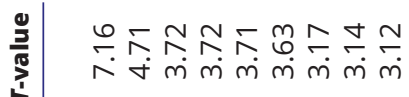

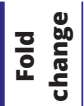

:

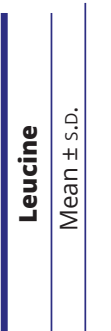

훌

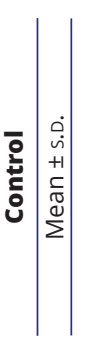

ฮั

힌

음 $\times \times \times \times \times \times \times \times \times$

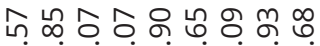

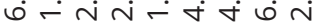

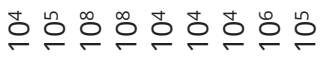
$\times \times \times \times \times \times \times \times$

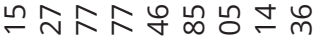
ヘ่mm-

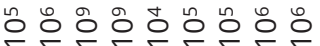
$\times \times x \times x \times x \times x$

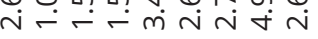

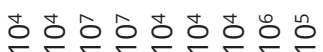
$\times \times \times \times \times x \times x \times$

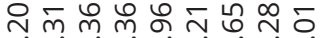

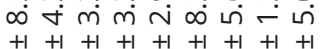

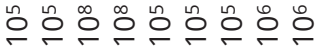

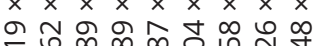

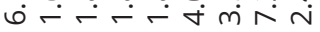

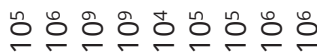
$x \times x \times x \times x \times x$

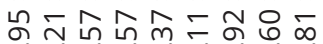
N

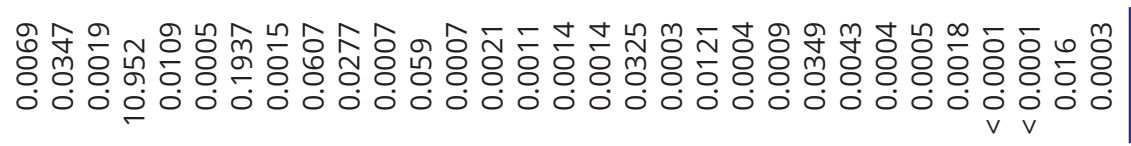

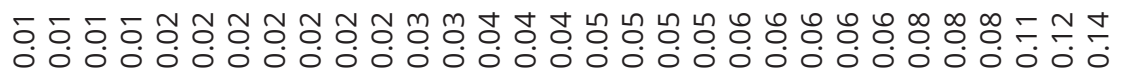

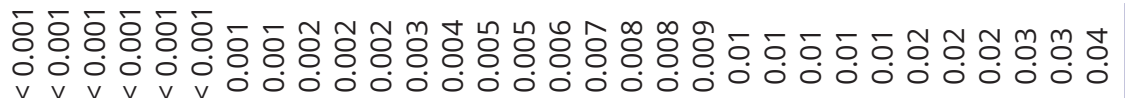

舟守

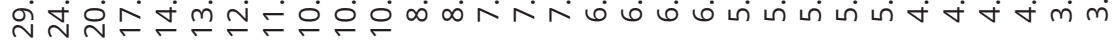

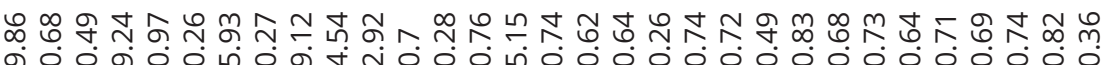

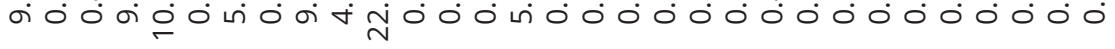

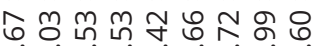

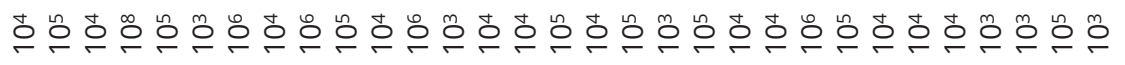

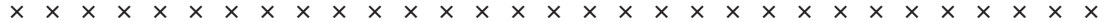
Ұ ம

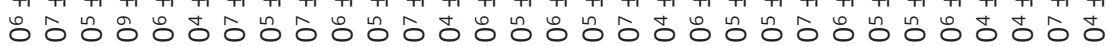

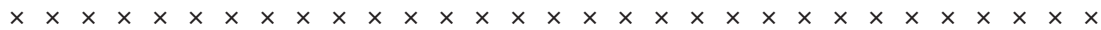
ळ

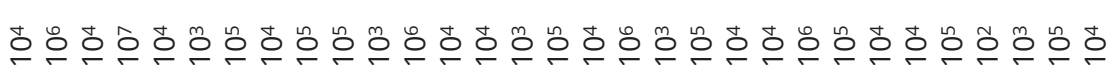

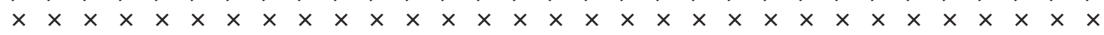

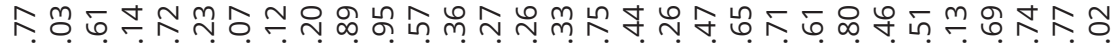

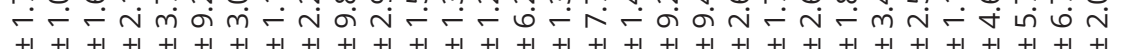

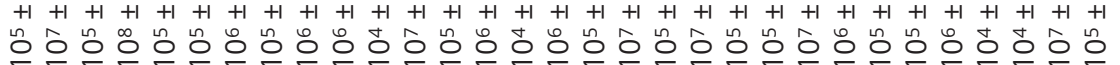

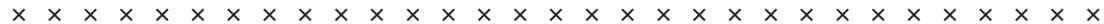

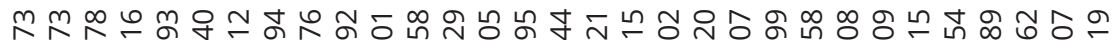
-

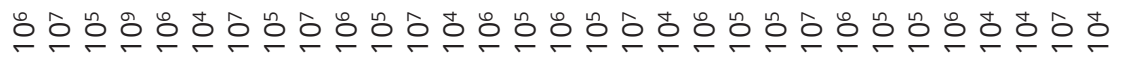
$x \times x \times x \times x \times x \times x \times x \times x \times x \times x \times x \times x \times x \times x \times x \times x$ চ

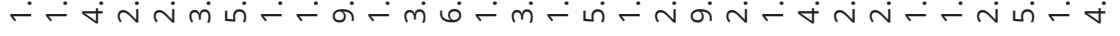

绩응

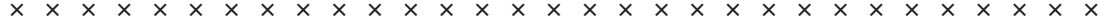
๓

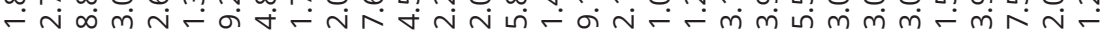

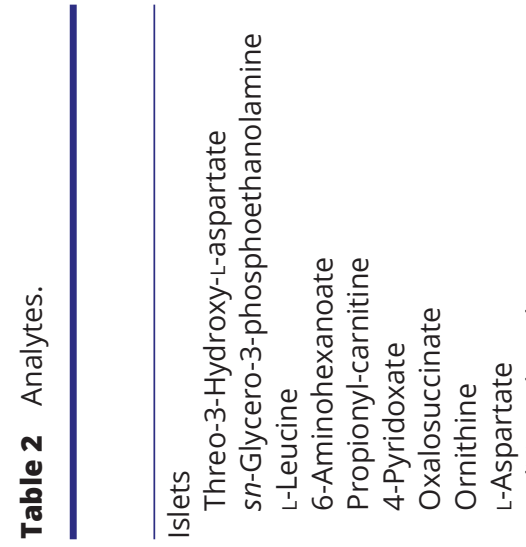

https://joe.bioscientifica.com https://doi.org/10.1530/JOE-20-0243
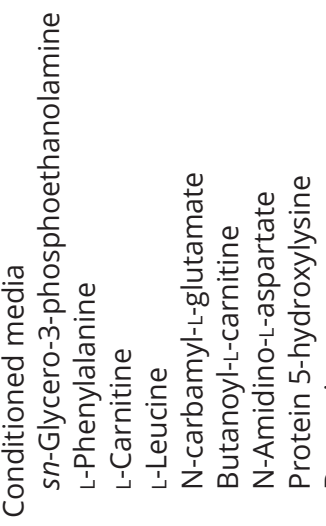

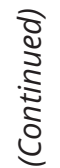




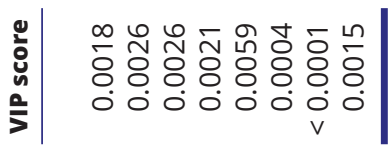

菌|

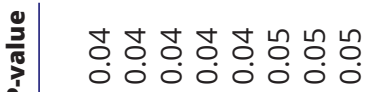

茜|

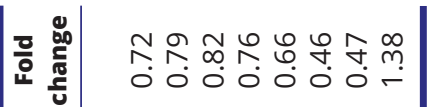

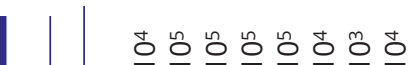

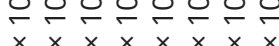

舟

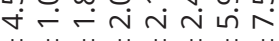

$+1+1+1+1+1+1+1+1$

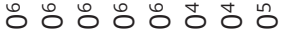

$\times \times \times \times \times \times \times$

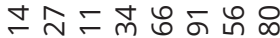

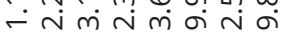

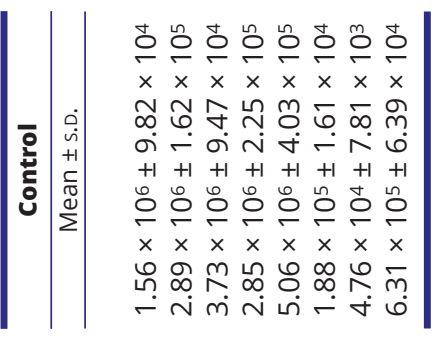

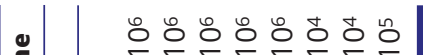

$\times \times \times \times \times \times x \times$

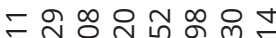

- viñ mín

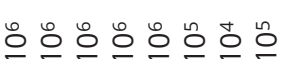

$\times \times x \times x \times x$

華嗢

- i mं vं

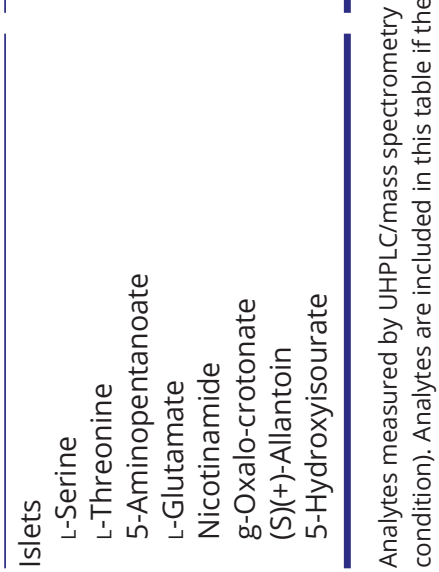

https://joe.bioscientifica.com

(C) 2020 Society for Endocrinology Published by Bioscientifica Ltd. Printed in Great Britain
A

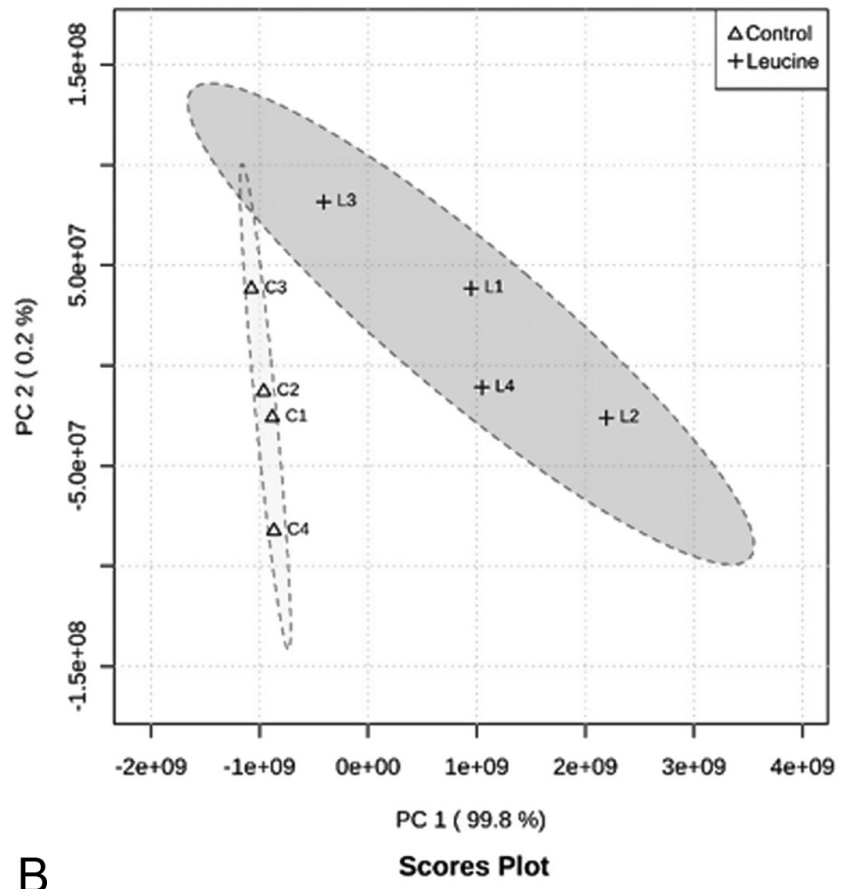

B

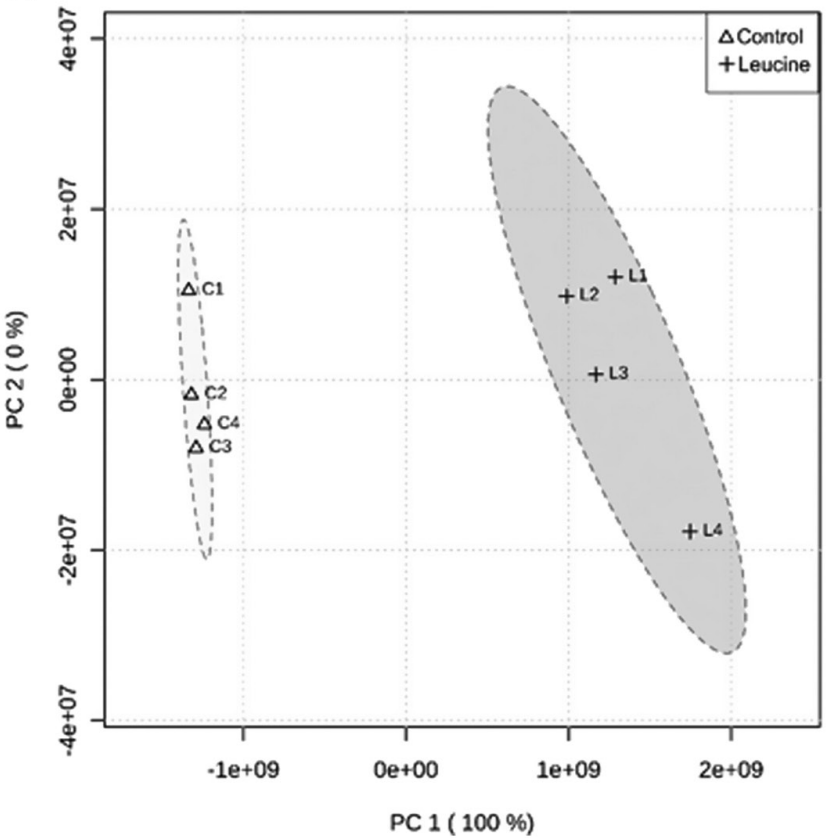

Figure 4

Fetal islet and islet media principal component analysis. Fetal sheep islets from four animals were divided into two equal aliquots and incubated in control media (C1-4) or control media supplemented with leucine (10 mmol/L; L1-4). UHPLC was used to determine the relative abundance of 140 analytes in the islets and 120 analytes in the media. Principal component (PC) analysis of the islet analytes (A) and media analytes (B) are shown.

amino acids, not just leucine. Of the seven significantly enriched pathways $(P \leq 0.05$ and an FDR $<0.25)$, six are directly involved in amino acid metabolism such as nitrogen 
Table 3 Metaboanalyst pathway analysis of analytes from the conditioned media.

\begin{tabular}{|c|c|c|c|c|c|c|c|}
\hline Pathway & $\begin{array}{c}\text { Total } \\
\text { compounds }\end{array}$ & Hits & P-value (raw) & $\log (p) \times-1$ & Holm P-value & FDR & Impact \\
\hline Aminoacyl-tRNA biosynthesis & 48 & 10 & $4.29 E-08$ & 16.965 & $3.60 \mathrm{E}-06$ & $\overline{3.60 \mathrm{E}-06}$ & 0.1667 \\
\hline Arginine and proline metabolism & 38 & 6 & 0.00016443 & 8.713 & 0.013648 & 0.005833 & 0.3393 \\
\hline Arginine biosynthesis & 14 & 4 & 0.0002083 & 8.4765 & 0.017081 & 0.005833 & 0.1777 \\
\hline $\begin{array}{l}\text { Valine, leucine and isoleucine } \\
\text { biosynthesis }\end{array}$ & 8 & 3 & 0.00059553 & 7.4261 & 0.048238 & 0.012506 & 0 \\
\hline Nitrogen metabolism & 6 & 2 & 0.0074218 & 4.9033 & 0.59374 & 0.1039 & 0 \\
\hline D-Glutamine and D-glutamate metabolism & 6 & 2 & 0.0074218 & 4.9033 & 0.59374 & 0.1039 & 0.5 \\
\hline Vitamin B6 metabolism & 9 & 2 & 0.017046 & 4.0718 & 1 & 0.20456 & 0.4902 \\
\hline $\begin{array}{l}\text { Alanine, aspartate and glutamate } \\
\text { metabolism }\end{array}$ & 28 & 3 & 0.025307 & 3.6767 & 1 & 0.26572 & 0.5345 \\
\hline Glyoxylate and dicarboxylate metabolism & 32 & 3 & 0.035962 & 3.3253 & 1 & 0.32708 & 0.0423 \\
\hline $\begin{array}{l}\text { Glycine, serine and threonine } \\
\text { metabolism }\end{array}$ & 33 & 3 & 0.038938 & 3.2458 & 1 & 0.32708 & 0.2171 \\
\hline Nicotinate and nicotinamide metabolism & 15 & 2 & 0.045562 & 3.0887 & 1 & 0.34793 & 0.1943 \\
\hline Histidine metabolism & 16 & 2 & 0.051323 & 2.9696 & 1 & 0.35926 & 0 \\
\hline Pyrimidine metabolism & 39 & 3 & 0.059332 & 2.8246 & 1 & 0.38338 & 0.1204 \\
\hline Pantothenate and CoA biosynthesis & 19 & 2 & 0.070037 & 2.6587 & 1 & 0.42022 & 0 \\
\hline $\begin{array}{l}\text { Phenylalanine, tyrosine and tryptophan } \\
\text { biosynthesis }\end{array}$ & 4 & 1 & 0.0898 & 2.4102 & 1 & 0.50288 & 0.5 \\
\hline Glutathione metabolism & 28 & 2 & 0.13613 & 1.9941 & 1 & 0.71469 & 0.0197 \\
\hline Cysteine and methionine metabolism & 33 & 2 & 0.17718 & 1.7306 & 1 & 0.8755 & 0.1263 \\
\hline Phenylalanine metabolism & 10 & 1 & 0.20998 & 1.5608 & 1 & 0.97988 & 0.3571 \\
\hline Valine, leucine and isoleucine degradation & 40 & 2 & 0.23735 & 1.4382 & 1 & 1 & 0 \\
\hline Butanoate metabolism & 15 & 1 & 0.29821 & 1.21 & 1 & 1 & 0 \\
\hline Selenocompound metabolism & 20 & 1 & 0.37683 & 0.97596 & 1 & 1 & 0.1591 \\
\hline Beta-alanine metabolism & 21 & 1 & 0.39149 & 0.93779 & 1 & 1 & 0 \\
\hline Sphingolipid metabolism & 21 & 1 & 0.39149 & 0.93779 & 1 & 1 & 0 \\
\hline Lysine degradation & 25 & 1 & 0.44686 & 0.80551 & 1 & 1 & 0 \\
\hline Purine metabolism & 65 & 2 & 0.45092 & 0.79646 & 1 & 1 & 0 \\
\hline Porphyrin and chlorophyll metabolism & 30 & 1 & 0.50922 & 0.67488 & 1 & 1 & 0 \\
\hline Glycerophospholipid metabolism & 36 & 1 & 0.57506 & 0.55328 & 1 & 1 & 0.015 \\
\hline $\begin{array}{l}\text { Amino sugar and nucleotide sugar } \\
\text { metabolism }\end{array}$ & 37 & 1 & 0.58516 & 0.53586 & 1 & 1 & 0 \\
\hline Tyrosine metabolism & 42 & 1 & 0.63228 & 0.45842 & 1 & 1 & 0.1297 \\
\hline
\end{tabular}

Pathways identified by metaboanalyst in the conditioned media after incubation in control or leucine supplemented media ( $n=4$ sets of islets split and incubated in each condition).

metabolism $(P<0.01)$ and the most significantly enriched pathway, the aminoactyl-tRNA biosynthesis pathway $\left(P<5 \times 10^{-8}\right.$; Table 3). Key analytes which met the criteria of a nominal $P$ value $\leq 0.05$ (Table 2 ) included leucine (ninefold higher in leucine supplemented conditioned media, $P<0.001)$ consistent with the experimental design and the HPLC results. Also consistent with the HPLC results were lower phenylalanine, valine, aspartate, methionine, proline, glutamine, serine, threonine, and glutamate. Additionally, analytes such as butanoyl-L-carnitine, acetylcarnitine, and propionyl-carnitine were all significantly lower in the leucine supplemented group $(P<0.05$, Table 2 ). Dopamine was nine-fold higher in the media obtained from leucine supplemented islets compared to nonsupplemented islets ( $P<0.005$; Fig. 5$)$. There was a tendency for higher dopamine (five-fold) and lower acetylcholine in leucine supplemented islets as well ( $P \leq 0.07$; Fig. 5).

(c) 2020 Society for Endocrinology Published by Bioscientifica Ltd. Printed in Great Britain

\section{Discussion}

The primary goal of this study was to test whether leucine acutely potentiates in vivo fetal GSIS. This goal complements our previous work demonstrating potentiated fetal GSIS with a chronic 9 days leucine infusion (Boehmer et al. 2020). That study showed important structural changes in the fetal pancreas. These may have been responsible for the increased GSIS. That study did not determine the impact of an acute fetal leucine infusion on GSIS, nor did it test the impact of supplemental leucine on in vitro fetal islet metabolism (Boehmer et al. 2020). Therefore, we also sought to determine if isolated fetal sheep islets have the capacity to oxidize leucine and if leucine can increase cellular metabolism in isolated fetal islets. Our results indicate that isolated fetal sheep islets oxidize leucine as evidenced 

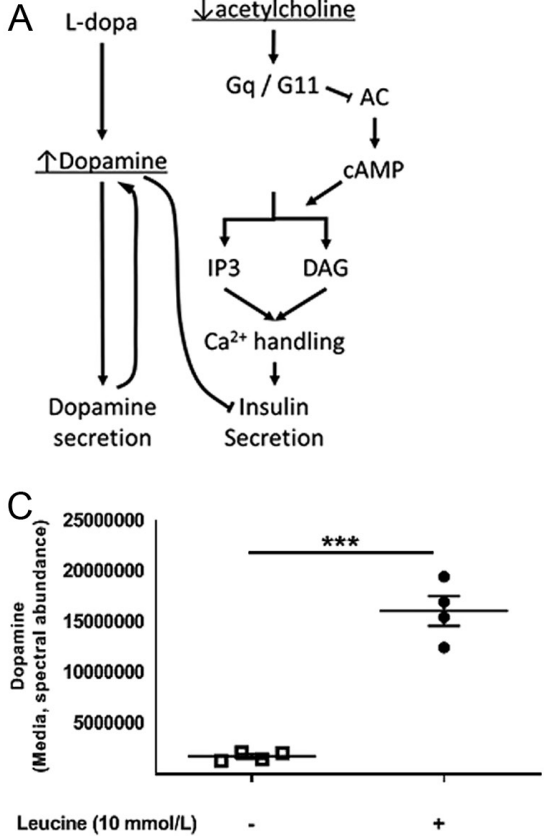
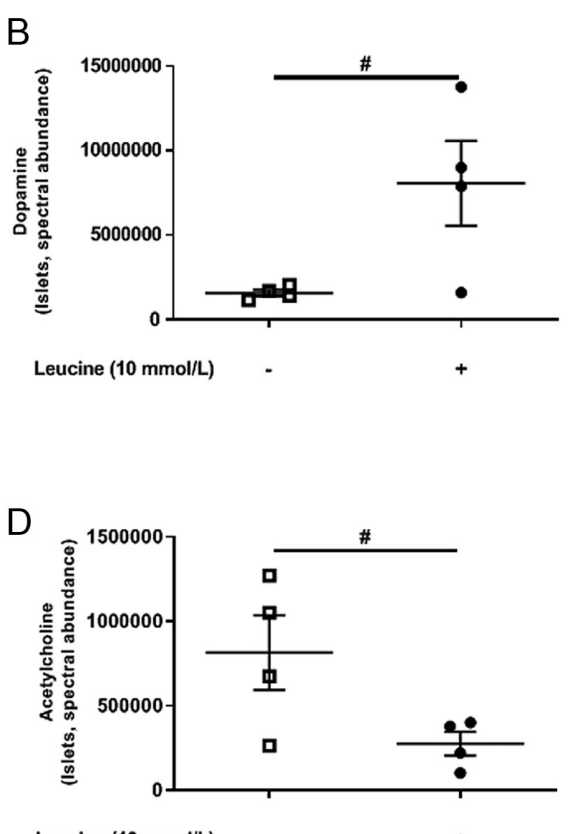

\section{Figure 5}

Leucine increases islet production of dopamine and decreases actetylcholine. (A) Schematic representation of pathways related to dopamine and acetylcholine regulation of insulin secretion. Underlined text represents higher or lower abundance in leucine supplemented conditions relative to non-supplemented conditions as indicated by the preceding arrow. Abundance of dopamine was higher following leucine supplementation relative to non-supplemented conditions in islets (B) and media (C), relative to non-supplemented conditions. Islet abundance of acetylcholine was lower in leucine supplemented conditions relative to non-supplemented conditions (D). Data were analyzed in Metaboanalyst and presented as means \pm S.E.M. $P$ values for paired t-test on four sets of islet incubations are presented as insets in the graphs. $\# P<0.1, * * * P<0.005$. by production of ${ }^{14} \mathrm{CO}_{2}$ from $\left[1-{ }^{14} \mathrm{C}\right]$ L-leucine in a $2 \mathrm{~h}$ incubation. Incubating isolated fetal sheep islets overnight in supplemental leucine demonstrated metabolic effects beyond leucine oxidation. Concentrations of almost all amino acids and glucose in the media obtained following islet incubations without supplemental leucine were lower than the control media that was not exposed to islets. Importantly, supplemental leucine resulted in amino acid and glucose concentrations that were even lower. It is reasonable to assume that the supplemental leucine stimulated cellular amino acid and glucose uptake from the media. The notable exception to this was isoleucine. Isoleucine concentrations were higher in media following overnight incubation with supplemental leucine relative to non-supplemented media. This likely reflects the competitive inhibition of isoleucine transport into the cells by leucine as these two branched chain amino acids (BCAAs) enter cells through similar sets of amino acid transporters (Javed \& Fairweather 2019). Our analysis with UHPLC/mass spectrometry is in agreement with the results and demonstrates a pattern consistent with an overall increase in cellular amino acid metabolism.

To demonstrate the capacity of leucine to acutely potentiate GSIS in vivo, we performed fetal insulin secretion studies in pregnant sheep. GSIS was measured in five sheep fetuses with a 90-min variable rate, squarewave, fetal hyperglycemic clamp with or without a concurrent acute leucine infusion that began 90 min prior to the hyperglycemic clamp. Prior to the hyperglycemic clamp, the leucine infusion minimally increased insulin concentrations compared to the control saline infusion. However, the difference in insulin concentrations between the leucine infusion and control saline infusion was pronounced during the hyperglycemic clamp. These data are consistent with our previous reports demonstrating that supplemental leucine on its own is a weak fetal insulin secretagogue (Rozance et al. 2006, Boehmer et al. 2020), and are also consistent with the minimal changes in media insulin concentrations following islet incubation with supplemental leucine observed in the current study. However, when combined with supplemental glucose, leucine robustly potentiates fetal GSIS.

The relative expression of analytes demonstrated that pathways most impacted by supplemental leucine involved amino acid metabolism, and not just leucine or BCAA metabolism. Over half of the significantly impacted pathways identified with Metaboanalyst using the KEGG database for annotation are directly involved in amino acid metabolism. Most of these pathways are associated with amino acids other than leucine. Amino acid, tricarboxylic acid cycle, and pyrimidine metabolic pathways have all been implicated in the glucose-stimulated insulin secretory response in insulin-secreting cell lines (Huang \& Joseph 2012, Lorenz et al. 2013). Other interesting findings from the UHPLC/mass spectrometry analysis were decreased acetylcholine and increased dopamine concentrations following incubation with supplemental leucine. Acetylcholine modifies $\beta$-cell calcium signaling to enhance insulin secretion, and low intracellular acetylcholine concentrations inhibit insulin secretion 
(Gilon \& Henquin 2001). Enriched dopamine signaling implicates a dopamine feedback mechanism that also is inhibitory for insulin secretion. Dopamine is co-secreted with insulin from $\beta$-cells, and serves as an autocrine signal to inhibit insulin secretion (Shankar et al. 2006, GarciaTornadu et al. 2010, Ustione et al. 2013). While these inhibitory signals may seem counter to the potentiation of in vivo and in vitro GSIS, it may be that without excess glucose these pathways are partly responsible for the lack of a consistent or large effect of supplemental leucine only on media insulin concentrations following the overnight islet incubations and on fetal insulin concentrations prior to the commencement of the hyperglycemic clamp despite active metabolism of leucine and other substrates. Once supplemental glucose is provided, these inhibitory pathways are overcome by pathways which stimulate GSIS.

The implications of our findings for the regulation of fetal growth and metabolism by the fetal nutrient supply are several fold. Insulin is a dominant fetal growth hormone, especially during the latter part of gestation (Fowden 1992). Similar to adults, human fetuses also are characterized by the capacity to respond to a hyperglycemic challenge with increased insulin concentrations (Nicolini et al. 1990). Numerous studies in fetal sheep have also demonstrated not only GSIS, but also amino acid stimulated insulin secretion (Fowden 1980, Aldoretta et al. 1998, Rozance et al. 2006, Brown et al. 2016) and amino acid potentiated GSIS (Gadhia et al. 2013, Brown et al. 2016). Therefore, the fetal $\beta$-cell can be seen as matching secretion of an anabolic growth hormone (insulin) with the fetal nutrient supply and nutrient availability (Boehmer et al. 2017). Disorders of fetal growth, such as intrauterine growth restriction from placental insufficiency, are characterized by lower rates of fetal nutrient supply and lower concentrations of insulin (Nicolini et al. 1990, Marconi et al. 1999, Paolini et al. 2001, Limesand et al. 2006, Wai et al. 2018). Strategies to improve fetal growth which directly target the pancreatic $\beta$-cell to produce more insulin have been considered (Brown et al. 2011). We have previously demonstrated that infusion of a complete amino acid mixture, both acutely and chronically, potentiates fetal GSIS in normal and IUGR fetuses (Gadhia et al. 2013, Brown et al. 2016). In the current study we chose to focus on leucine because of its potential for stimulating pancreatic islet growth, development, and insulin secretion (Rozance \& Hay Jr 2016, Boehmer et al. 2017); and because of its ability to potentiate fetal GSIS following a chronic 9-day infusion (Boehmer et al. 2020). Our results show that supplemental leucine without supplementation of other nutrients has a minimal impact on fetal insulin concentrations. Strategies which chronically increase the fetal leucine supply with other nutrients like glucose hold more promise for increasing fetal insulin secretion.

\section{Supplementary materials}

This is linked to the online version of the paper at https://doi.org/10.1530/ JOE-20-0243.

\section{Declaration of interest}

The authors declare that there is no conflict of interest that could be perceived as prejudicing the impartiality of the research reported.

\section{Funding}

This work was supported by the National Institute of Health Grants R01DK088139 (P J R), R01HD093701 (P J R), T32HD007186 (BHB trainee, P J R PI), R01DK108910 (S R W), R01HD079404 (L D B), S100D023553 (L D B).

\section{Author contribution statement}

All authors approved the submission of the manuscript and contributed as follows: $\mathrm{B} H \mathrm{~B}$ and $\mathrm{P} \mathrm{J}$ R conceived of the experimental design; $\mathrm{B} \mathrm{H} \mathrm{B}$, $P R B$, and P J R conducted experiments and statistical analyses; $B$ H B and P J R wrote the first draft of the manuscript; $B H B, P R B, L D B, S R$, and $P J R$ participated in data analysis, proofread the manuscript, and approved the final manuscript.

\section{References}

Aldoretta PW, Carver TD \& Hay Jr WW 1998 Maturation of glucosestimulated insulin secretion in fetal sheep. Biology of the Neonate 73 375-386. (https://doi.org/10.1159/000014000)

Benjamin JS, Culpepper CB, Brown LD, Wesolowski SR, Jonker SS, Davis MA, Limesand SW, Wilkening RB, Hay Jr WW \& Rozance PJ 2017 Chronic anemic hypoxemia attenuates glucose-stimulated insulin secretion in fetal sheep. American Journal of Physiology: Regulatory, Integrative and Comparative Physiology 312 R492-R500. (https://doi.org/10.1152/ajpregu.00484.2016)

Boehmer BH, Limesand SW \& Rozance PJ 2017 The impact of IUGR on pancreatic islet development and beta-cell function. Journal of Endocrinology 235 R63-R76. (https://doi.org/10.1530/JOE-17-0076)

Boehmer BH, Brown LD, Wesolowski SR, Hay WW \& Rozance PJ 2020 A chronic fetal leucine infusion potentiates fetal insulin secretion and increases pancreatic islet size, vascularity, and beta cells in lategestation sheep. Journal of Nutrition 150 2061-2069. (https://doi. org/10.1093/jn/nxaa138)

Brown LD, Green AS, Limesand SW \& Rozance PJ 2011 Maternal amino acid supplementation during pregnancy for intrauterine growth restriction. Frontiers in Bioscience Supplement 3 428-444. (https://doi. $\operatorname{org} / 10.2741 / \mathrm{s} 162$ )

Brown LD, Rozance PJ, Thorn SR, Friedman JE \& Hay Jr WW 2012 Acute supplementation of amino acids increases net protein accretion in IUGR fetal sheep. American Journal of Physiology: Endocrinology and Metabolism 303 E352-E364. (https://doi.org/10.1152/ajpendo.00059.2012)

Brown LD, Davis M, Wai S, Wesolowski SR, Hay Jr WW, Limesand SW \& Rozance PJ 2016 Chronically increased amino acids improve insulin secretion, pancreatic vascularity and islet size in growth restricted 
fetal sheep. Endocrinology 157 3788-3799. (https://doi.org/10.1210/ en.2016-1328)

Culpepper C, Wesolowski SR, Benjamin J, Bruce JL, Brown LD, Jonker SS, Wilkening RB, Hay Jr WW \& Rozance PJ 2016 Chronic anemic hypoxemia increases plasma glucagon and hepatic PCK1 mRNA in late-gestation fetal sheep. American Journal of Physiology: Regulatory, Integrative and Comparative Physiology 311 R200-R208. (https://doi. org/10.1152/ajpregu.00037.2016)

Fajans SS, Floyd Jr JC, Knopf RF, Guntsche EM, Rull JA, Thiffault CA \& Conn JW 1967 A difference in mechanism by which leucine and other amino acids induce insulin release. Journal of Clinical Endocrinology and Metabolism 27 1600-1606. (https://doi.org/10.1210/jcem-27-11-1600)

Fowden AL 1980 Effects of adrenaline and amino acids on the release of insulin in the sheep fetus. Journal of Endocrinology 87 113-121. (https://doi.org/10.1677/joe.0.0870113)

Fowden AL 1992 The role of insulin in fetal growth. Early Human Development 29 177-181. (https://doi.org/10.1016/03783782(92)90135-4)

Gadhia MM, Maliszewski AM, O'Meara MC, Thorn SR, Lavezzi JR, Limesand SW, Hay Jr WW, Brown LD \& Rozance PJ 2013 Increased amino acid supply potentiates glucose-stimulated insulin secretion but does not increase beta-cell mass in fetal sheep. American Journal of Physiology: Endocrinology and Metabolism 304 E352-E362. (https://doi. org/10.1152/ajpendo.00377.2012)

Gao Z, Young RA, Li G, Najafi H, Buettger C, Sukumvanich SS, Wong RK, Wolf BA \& Matschinsky FM 2003 Distinguishing features of leucine and alpha-ketoisocaproate sensing in pancreatic beta-cells. Endocrinology 144 1949-1957. (https://doi.org/10.1210/en.2002-0072)

Garcia-Tornadu I, Ornstein AM, Chamson-Reig A, Wheeler MB, Hill DJ, Arany E, Rubinstein M \& Becu-Villalobos D 2010 Disruption of the dopamine $\mathrm{d} 2$ receptor impairs insulin secretion and causes glucose intolerance. Endocrinology 151 1441-1450. (https://doi.org/10.1210/ en.2009-0996)

Gilon P \& Henquin JC 2001 Mechanisms and physiological significance of the cholinergic control of pancreatic beta-cell function. Endocrine Reviews 22 565-604. (https://doi.org/10.1210/edrv.22.5.0440)

Hochberg Y \& Benjamini Y 1990 More powerful procedures for multiple significance testing. Statistics in Medicine 9 811-818. (https://doi. org/10.1002/sim.4780090710)

Huang M \& Joseph JW 2012 Metabolomic analysis of pancreatic beta-cell insulin release in response to glucose. Islets 4 210-222. (https://doi. org/10.4161/isl.20141)

Javed K \& Fairweather SJ 2019 Amino acid transporters in the regulation of insulin secretion and signalling. Biochemical Society Transactions $\mathbf{4 7}$ 571-590. (https://doi.org/10.1042/BST20180250)

Li C, Najafi H, Daikhin Y, Nissim IB, Collins HW, Yudkoff M, Matschinsky FM \& Stanley CA 2003 Regulation of leucinestimulated insulin secretion and glutamine metabolism in isolated rat islets. Journal of Biological Chemistry 278 2853-2858. (https://doi. org/10.1074/jbc.M210577200)

Limesand SW, Rozance PJ, Zerbe GO, Hutton JC \& Hay Jr WW 2006 Attenuated insulin release and storage in fetal sheep pancreatic islets with intrauterine growth restriction. Endocrinology 147 1488-1497. (https://doi.org/10.1210/en.2005-0900)

Lorenz MA, El Azzouny MA, Kennedy RT \& Burant CF 2013 Metabolome response to glucose in the beta-cell line INS-1 832/13. Journal of Biological Chemistry 288 10923-10935. (https://doi.org/10.1074/jbc.M112.414961)

Malaisse WJ, Sener A, Herchuelz A \& Hutton JC 1979 Insulin release: the fuel hypothesis. Metabolism: Clinical and Experimental 28 373-386. (https://doi.org/10.1016/0026-0495(79)90111-2)
Malaisse WJ, Hutton JC, Carpinelli AR, Herchuelz A \& Sener A 1980 The stimulus-secretion coupling of amino acid-induced insulin release: metabolism and cationic effects of leucine. Diabetes 29 431-437. (https://doi.org/10.2337/diab.29.6.431)

Marconi AM, Paolini CL, Stramare L, Cetin I, Fennessey PV, Pardi G \& Battaglia FC 1999 Steady state maternal-fetal leucine enrichments in normal and intrauterine growth-restricted pregnancies. Pediatric Research 46 114-119. (https://doi.org/10.1203/00006450-19990700000019)

McClenaghan NH, Barnett CR, O'Harte FP \& Flatt PR 1996 Mechanisms of amino acid-induced insulin secretion from the glucose-responsive BRIN-BD11 pancreatic B-cell line. Journal of Endocrinology $\mathbf{1 5 1}$ 349-357. (https://doi.org/10.1677/joe.0.1510349)

Nemkov T, D'Alessandro A \& Hansen KC 2015 Three-minute method for amino acid analysis by UHPLC and high-resolution quadrupole Orbitrap mass spectrometry. Amino Acids 47 2345-2357. (https://doi. org/10.1007/s00726-015-2019-9)

Nemkov T, Hansen KC \& D'Alessandro A 2017 A three-minute method for high-throughput quantitative metabolomics and quantitative tracing experiments of central carbon and nitrogen pathways. Rapid Communications in Mass Spectrometry 31 663-673. (https://doi. $\operatorname{org} / 10.1002 / \mathrm{rcm} .7834$ )

Nicolini U, Hubinont C, Santolaya J, Fisk NM \& Rodeck CH 1990 Effects of fetal intravenous glucose challenge in normal and growth retarded fetuses. Hormone and Metabolic Research 22 426-430. (https://doi. org/10.1055/s-2007-1004939)

Paolini CL, Marconi AM, Ronzoni S, Di Noio M, Fennessey PV, Pardi G \& Battaglia FC 2001 Placental transport of leucine, phenylalanine, glycine, and proline in intrauterine growth-restricted pregnancies. Journal of Clinical Endocrinology and Metabolism 86 5427-5432. (https://doi.org/10.1210/jcem.86.11.8036)

Rozance PJ \& Hay Jr WW 2016 Pancreatic islet hepatocyte growth factor and vascular endothelial growth factor A signaling in growth restricted fetuses. Molecular and Cellular Endocrinology 435 78-84. (https://doi.org/10.1016/j.mce.2016.01.025)

Rozance PJ, Limesand SW \& Hay Jr WW 2006 Decreased nutrientstimulated insulin secretion in chronically hypoglycemic lategestation fetal sheep is due to an intrinsic islet defect. American Journal of Physiology: Endocrinology and Metabolism 291 E404-E411. (https://doi.org/10.1152/ajpendo.00643.2005)

Rozance PJ, Limesand SW, Zerbe GO \& Hay Jr WW 2007 Chronic fetal hypoglycemia inhibits the later steps of stimulus-secretion coupling in pancreatic beta-cells. American Journal of Physiology: Endocrinology and Metabolism 292 E1256-E1264. (https://doi.org/10.1152/ ajpendo.00265.2006)

Sener A \& Malaisse WJ 1980 L-leucine and a nonmetabolized analogue activate pancreatic islet glutamate dehydrogenase. Nature $\mathbf{2 8 8}$ 187-189. (https://doi.org/10.1038/288187a0)

Shankar E, Santhosh KT \& Paulose CS 2006 Dopaminergic regulation of glucose-induced insulin secretion through dopamine D2 receptors in the pancreatic islets in vitro. IUBMB Life 58 157-163. (https://doi. org/10.1080/15216540600687993)

Ustione A, Piston DW \& Harris PE 2013 Minireview: dopaminergic regulation of insulin secretion from the pancreatic islet. Molecular Endocrinology 27 1198-1207. (https://doi.org/10.1210/me.2013-1083)

Wai SG, Rozance PJ, Wesolowski SR, Hay Jr WW \& Brown LD 2018 Prolonged amino acid infusion into intrauterine growth-restricted fetal sheep increases leucine oxidation rates. American Journal of Physiology: Endocrinology and Metabolism 315 E1143-E1153. (https:// doi.org/10.1152/ajpendo.00128.2018)

Received in final form 23 July 2020

Accepted 4 August 2020

Accepted Manuscript published online 4 August 2020 https://joe.bioscientifica.com https://doi.org/10.1530/JOE-20-0243 (c) 2020 Society for Endocrinology Published by Bioscientifica Ltd. Printed in Great Britain 